\title{
Overexpression of the HCN2 channel increases the arrhythmogenicity induced by hypokalemia
}

\author{
Kensuke Oshita ${ }^{1,2} \cdot$ Yuko Kozasa $^{1,2} \cdot$ Yasuaki Nakagawa ${ }^{3} \cdot$ Yoshihiro Kuwabara $^{3} \cdot$ Koichiro Kuwahara $^{4}$. \\ Taku Nakagawa ${ }^{1} \cdot$ Noriyuki Nakashima $^{1} \cdot$ Teruyuki Hiraki $^{2} \cdot$ Makoto Takano' $^{1}$
}

Received: 18 March 2019 / Accepted: 30 April 2019 / Published online: 13 May 2019

(c) The Author(s) 2019

\begin{abstract}
Hypokalemia, an abnormally low level of potassium $\left(\mathrm{K}^{+}\right)$, is a electrolyte imbalance that commonly occurs in heart failure patients. Hypokalemia is well known to induce lethal ventricular arrhythmia. However, the effects of hypokalemia in failing hearts that have undergone electrophysiological remodeling, i.e., the reactivation of fetal-type ion channels, remain unexplored. We have examined the effect of hypokalemia in the myocytes of transgenic mice overexpressing the hyperpolarizationactivated, cyclic nucleotide-sensitive ( $\mathrm{HCN})$ channel in the heart (HCN2-Tg mice). Perfusion with a mild hypokalemic solution containing $3 \mathrm{mM} \mathrm{K}^{+}$induced ectopic ventricular automaticity in $55.0 \%$ of HCN2-Tg mouse myocytes. In the remaining HCN2-Tg mouse myocytes, the resting membrane potential (RMP) was more depolarized than that of wild-type myocytes subjected to the same treatment and could also be hyperpolarized by an $\mathrm{HCN}$ channel blocker. We conclude that in hypokalemia in our mice model, the HCN2 channel was constitutively activated at the hyperpolarized RMP, thereby destabilizing the electrophysiological activity of ventricular myocytes.
\end{abstract}

Keywords Hypokalemia $\cdot$ Arrhythmia $\cdot \mathrm{HCN} 2 \cdot$ Heart failure

\section{Introduction}

Hypokalemia, a type of pro-arrhythmic electrolyte disturbance characterized by an abnormally low level of potassium $\left(\mathrm{K}^{+}\right)$, is frequently observed in patients with cardiovascular disease [1, 2]. Heart failure patients in particular often receive diuretics, some of which can cause an increase in the elimination of $\mathrm{K}^{+}$in the urine, leading to hypokalemia. Almost 50\% of heart failure patients die suddenly, most probably due to ventricular arrhythmia. Therefore, it is important to control the serum potassium homeostasis

Makoto Takano

takanom@med.kurume-u.ac.jp

1 Department of Physiology, Kurume University School of Medicine, 67 Asahi-Machi, Kurume 830-0011, Japan

2 Department of Anesthesiology, Kurume University School of Medicine, Kurume, Japan

3 Department of Cardiovascular Medicine, Kyoto University Graduate School of Medicine, Kyoto, Japan

4 Department of Cardiovascular Medicine, Shinshu University School of Medicine, Matsumoto, Japan during the treatment of heart failure patients with arrhythmia $[3,4]$.

The mechanism of ventricular arrhythmia in heart failure is not fully understood. Calcium $\left(\mathrm{Ca}^{2+}\right)$ overload and pathological $\mathrm{Ca}^{2+}$ release from the sarcoplasmic reticulum is thought to induce inward $\mathrm{Na}^{+}-\mathrm{Ca}^{2+}$ exchanger currents, giving rise to delayed after-depolarization [5]. Electrophysiological remodeling, i.e., reactivation of fetal cardiac genes, including T-type $\mathrm{Ca}^{2+}$ channel and hyperpolarization-activated, cyclic nucleotide-sensitive (HCN) cation channels (HCN2 and -4) have also been reported to increase the vulnerability to arrhythmia $[6,7]$.

Hypokalemia hyperpolarizes the resting membrane potential (RMP) and prolongs the action potential duration (APD) of the ventricular myocytes [8]. Therefore, it appears likely that HCN2 channels, when re-expressed in the hypertrophied heart, may be activated at a hyperpolarized RMP under hypokalemic conditions and may thereby increase the arrhythmogenicity. We have previously reported that $\beta$-adrenergic stimulation induced ectopic ventricular automaticity in the hearts of transgenic mice overexpressing HCN2 (HCN2-Tg mice) [9]. In the present study, our aim was to examine the effects of hypokalemia 
on the ventricular myocytes isolated from $\mathrm{HCN} 2-\mathrm{Tg}$ mice. We also raised the HCN2-Tg mice on a $\mathrm{K}^{+}$-free diet, and compared their electrocardiograms (ECGs) with those of their wild-type (WT) littermates. We will demonstrate that HCN2 overexpression increases the vulnerability to arrhythmia under hypokalemic conditions. Preliminary results of the study reported here have been communicated to the annual meeting of the Physiological Society of Japan [10].

\section{Methods}

\section{Experimental animals}

To generate the HCN2-Tg mice, the cDNA of murine HCN2 was overexpressed in C57BL/6 mice using the alpha-MHC promoter (thereby generating HCN2-Tg mice), as reported previously [7]. We used the HCN2-Tg mice and their WT littermates aged between 10 and 30 weeks of age. The mice were raised in air-conditioned rooms at $25{ }^{\circ} \mathrm{C}$, under a 12/12-h light/dark cycle.

\section{Cell isolation}

After the mice were deeply anesthetized with 5\% sevoflurane, their hearts were quickly removed and perfused using a Langendorff apparatus. Single ventricular myocytes were obtained following collagenase digestion, as previously reported [9].

\section{Electrophysiological measurements}

The membrane current and action potentials (APs) were recorded using the ruptured whole-cell patch method with the Axopatch 200B amplifier and Digidata 1320 interface (Molecular Devices, San Jose, CA, USA). The electrode resistance of the patch pipette was 3-4 $M \Omega$ when filled with an internal, high- $\mathrm{K}^{+}$solution containing $110 \mathrm{mM}$ aspartic acid, $30 \mathrm{mM} \mathrm{KCl}, 5 \mathrm{mM} \mathrm{K}_{2} \mathrm{ATP}, 5 \mathrm{mM} \mathrm{Na}_{2}$ creatine phosphate, $0.1 \mathrm{mM} \mathrm{Na}_{2} \mathrm{GTP}, 5 \mathrm{mM}$ EGTA, $1 \mathrm{mM} \mathrm{MgCl}$, and $5 \mathrm{mM}$ HEPES (the $\mathrm{pH}$ was adjusted to 7.2 with $\mathrm{KOH}$ ). The final $\mathrm{K}^{+}$concentration of the internal pipette solution was $159.6 \mathrm{mM}$. The whole-cell patch was established in the bathing solution which contained $140 \mathrm{mM} \mathrm{NaCl}, 5.4 \mathrm{mM} \mathrm{KCl}$, $0.5 \mathrm{mM} \mathrm{MgCl}_{2}, 1.8 \mathrm{mM} \mathrm{CaCl}_{2}$, and $5 \mathrm{mM}$ HEPES (the $\mathrm{pH}$ was adjusted to 7.4 with $\mathrm{NaOH}$ ) at $33-34{ }^{\circ} \mathrm{C}$. Ivabradine (IVA; Santa Cruz Biotechnology, Inc., Dallas, TX, USA) stock solution $(10 \mathrm{mg} / \mathrm{ml})$ was prepared in distilled $\mathrm{H}_{2} \mathrm{O}$ and diluted to a concentration of $10 \mu \mathrm{M}$ in the bathing solution.

\section{ECG recording}

During the ECG recording, the mice were anesthetized using 3.0\% sevoflurane, and their body temperature was monitored and maintained at $37{ }^{\circ} \mathrm{C}$ using a warming device. We recorded two-lead ECGs (lead I and lead II) on the WT and HCN2-Tg mice that had been raised on a $\mathrm{K}^{+}$-free diet (Research Diets Inc., New Brunswick, NJ, USA) for 6 weeks. IVA ( $7 \mathrm{mg} / \mathrm{kg}$ per day) was dissolved in the drinking water that was supplied to the mice ad libitum for 6 weeks. The ECG waveforms were analyzed using the PowerLab Data Acquisition System and the LabChart software (ADInstruments Inc., Dunedin, New Zealand), as reported previously [9]. At the end of the ECG recordings, the mice were deeply anesthetized with $5.0 \%$ sevoflurane and then euthanized by aspirating the blood from the left ventricle. The blood was kept on ice for $15 \mathrm{~min}$, and the serum was obtained by centrifuging the blood samples at $1000 \mathrm{~g}$ for $5 \mathrm{~min}$ at $4{ }^{\circ} \mathrm{C}$. The serum $\mathrm{K}^{+}$concentration was measured using the ion-selective electrode method (Oriental Bio Inc., Gyeonggi-do, South Korea).

\section{Statistical analysis}

The results are expressed as the mean \pm standard deviation (SD). Statistical analysis was carried out using Students' paired $t$ test, unpaired $t$ test, and the $\chi^{2}$ test.

\section{Results}

\section{Spontaneous action potentials of HCN2-Tg mouse myocytes following induction with mild hypokalemic solution}

In ventricular myocytes, the RMP is primarily determined by the inward rectifier $\mathrm{K}^{+}$current $\left(I_{\mathrm{K} 1}\right)$ flowing through the Kir2.1 channel. As shown in Fig. 1a, the RMP of ventricular myocytes isolated from WT mice was hyperpolarized following the equilibrium potential for $\mathrm{K}^{+}\left(E_{\mathrm{K}}\right)$ when the bathing solution was switched from a normal Tyrode solution (extracellular $\mathrm{K}^{+}$concentration $\left[\mathrm{K}^{+}\right]_{\mathrm{o}}=5.4 \mathrm{mM}$ ) to a clinically relevant, mild hypokalemic solution $\left(\left[\mathrm{K}^{+}\right]_{0}=3 \mathrm{mM}\right)$. No spontaneous action potential (SAP) was observed under this condition ( 0 of 11 cells). We then induced the AP by current injection and examined the effects of the $3 \mathrm{mM}$ $\left[\mathrm{K}^{+}\right]_{\mathrm{o}}$ solution. Unlike the case for myocytes from guinea pigs or rabbits, the APD of murine ventricular myocytes at $90 \%$ repolarization $\left(\mathrm{APD}_{90}\right)$ was not markedly prolonged in the hypokalemic solution, when the AP was recorded using the ruptured whole-cell patch method with a pipette solution containing EGTA, a specific chelator for $\mathrm{Ca}^{2+}$, as shown in Fig. $1 \mathrm{~b}$ (blue line, in $5.4 \mathrm{mM}\left[\mathrm{K}^{+}\right]_{0}$; black line, in $3 \mathrm{mM}$ 
A

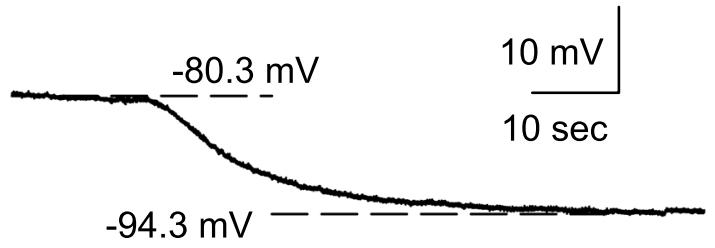

$3 \mathrm{mM} \mathrm{K}^{+}$
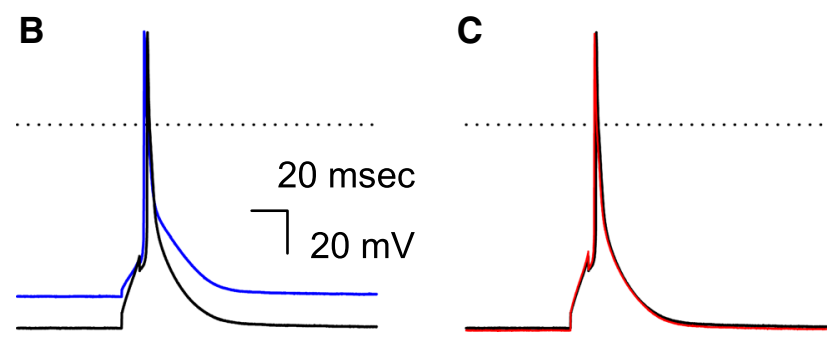

Fig. 1 Effect of mild hypokalemia on wild-type (WT) mouse myocytes. a Hyperpolarization of the resting membrane potential (RMP) of WT mouse myocytes. As indicated by the blue bar, the bathing solution was switched from the $5.4 \mathrm{mM}$ extracellular potassium $\left(\mathrm{K}^{+}\right)$ concentration $\left(\left[\mathrm{K}^{+}\right]_{0}\right)$ solution to the $3 \mathrm{mM}\left[\mathrm{K}^{+}\right]_{0}$ solution. b The induced action potention (AP) in the $5.4 \mathrm{mM}\left[\mathrm{K}^{+}\right]_{0}$ solution (blue line) and the $3 \mathrm{mM}\left[\mathrm{K}^{+}\right]_{\mathrm{o}}$ solution (black line). c The AP recorded in the same myocytes as those mentioned in $\mathbf{b}$ (the black line, control; the red line, in the presence of $10 \mu \mathrm{M}$ ivabradine [IVA]). The $\mathrm{K}^{+}$concentration of the bathing solution was $3 \mathrm{mM}$. The dotted line indicates $0 \mathrm{mV}$ (color figure online)

Table 1 The summary of the parameters of the induced action potential in wild-type myocytes

\begin{tabular}{lcrc}
\hline $\mathrm{WT}$ & $5.4 \mathrm{mM}\left[\mathrm{K}^{+}\right]_{\mathrm{o}}$ & $3 \mathrm{mM}\left[\mathrm{K}^{+}\right]_{\mathrm{o}}$ & $3 \mathrm{mM}\left[\mathrm{K}^{+}\right]_{\mathrm{o}}+\mathrm{IVA}$ \\
\hline $\mathrm{RMP}(\mathrm{mV})$ & $-81.5 \pm 1.0$ & $-95.0 \pm 2.2$ & $-94.5 \pm 1.1$ \\
$\mathrm{APD}_{90}(\mathrm{~ms})$ & $30.4 \pm 1.8$ & $31.5 \pm 1.2$ & $30.9 \pm 1.1$ \\
\hline
\end{tabular}

The summaries of RMP and $\mathrm{APD}_{90}$ in the $5.4 \mathrm{mM}\left[\mathrm{K}^{+}\right]_{\mathrm{o}}, 3 \mathrm{mM}$ $\left[\mathrm{K}^{+}\right]_{\mathrm{o}}$, and $3 \mathrm{mM}\left[\mathrm{K}^{+}\right]_{\mathrm{o}}$ solutions, all of which contain $10 \mu \mathrm{M}$ IVA $(n=6)$

$A P D_{90}$ Action potential duration at $90 \%$ repolarization, IVA ivabradine, $\left[K^{+}\right]_{0}$ extracellular $\mathrm{K}^{+}$concentration, $R M P$ resting membrane potential

$\left[\mathrm{K}^{+}\right]_{\mathrm{o}}$ ). This was presumably due to the voltage-gated $\mathrm{K}^{+}$ channels comprising the "repolarization reserve" of murine myocytes being less sensitive to hypokalemia (for detailed information, see section Limitations of the present study in the Discussion section). We further examined the effects of $10 \mu \mathrm{M}$ IVA (HCN channel blocker) on the AP. It is evident from Fig. 1c that the waveforms of APs in the presence (red line) and absence (black line) of IVA are superimposable. As summarized in Table 1, the application of IVA showed no significant effects on the RMP or $\mathrm{APD}_{90}$ of the WT myocytes.

We previously reported that the RMPs of HCN2-Tg mouse myocytes were not significantly different from those of WT mouse myocytes in normal Tyrode solution, but that they were depolarized by $\beta$-adrenergic stimulation, followed by the generation of SAPs [9]. Likewise, in $55.0 \%$ of the HCN2-Tg mouse myocytes examined, SAPs were immediately induced after perfusion with the $3 \mathrm{mM}\left[\mathrm{K}^{+}\right]_{0}$ bathing solution (11 of 20 cells; Fig. 2a, b); the application of $10 \mu \mathrm{M}$ IVA successfully terminated the SAPs induced by the $3 \mathrm{mM}$ $\left[\mathrm{K}^{+}\right]_{\mathrm{o}}$ solution. The inset of Fig. 2a shows the expanded tracing of the SAPs. In each myocyte, the maximal diastolic potentials (MDPs) and the firing rates (FRs) were calculated from ten successive SAPs; these are summarized in Fig. 2c (gray symbols). The averaged value of MDPs and FRs are indicated by the red symbol in Fig. 2c.

When HCN2-Tg mouse myocytes showed no SAPs in the $3 \mathrm{mM}\left[\mathrm{K}^{+}\right]_{\mathrm{o}}$ solution, we induced APs by current injection. Unlike the WT mouse myocytes, the magnitude of hyperpolarization induced by the hypokalemic solution was smaller, as shown by the blue line (in $5.4 \mathrm{mM}$ solution) and the black line (in the $3 \mathrm{mM}\left[\mathrm{K}^{+}\right]_{\mathrm{o}}$ solution) in Fig. 2d. Furthermore, the application of $10 \mu \mathrm{M}$ IVA consistently hyperpolarized the RMP of HCN2-Tg mouse myocytes and shortened the APD, as shown in Fig. 2e (the black line, control; the red line, $10 \mu \mathrm{M}$ IVA). The effect of the hypokalemic solution and $10 \mu \mathrm{M}$ IVA on the RMPs and $\mathrm{APD}_{90}$ of HCN2-Tg mouse myocytes is summarized in Table 2. Under the hypokalemic condition, the RMP was significantly hyperpolarized by IVA $(p<0.05 ; n=6)$; at the same time, IVA significantly shortened the $\mathrm{APD}_{90}(p<0.05 ; n=6)$. These findings strongly suggest that $\mathrm{HCN} 2$ channels overexpressed in the ventricular myocytes were constitutively activated at the RMP and participated as components of the repolarization reserve of HCN2-Tg mouse myocytes under hypokalemic conditions.

\section{The background membrane currents of HCN2-Tg mouse myocytes in a hypokalemic solution}

We had previously reported that neither the amplitudes of $I_{\mathrm{K} 1}$ nor the Kir2.1 mRNA levels of the WT and HCN2-Tg mouse myocytes were different [9]. Nevertheless, the RMP of HCN2-Tg mouse myocytes was more depolarized under hypokalemic conditions. In order to explore the ionic mechanisms of RMP depolarization under hypokalemic conditions, we compared the background currents of the WT and HCN2Tg mouse myocytes in the $3 \mathrm{mM}\left[\mathrm{K}^{+}\right]_{\mathrm{o}}$ solution. As shown in Fig. 3, hyperpolarizing pulse steps ranging from -50 to $-150 \mathrm{mV}$ were applied, and the amplitudes of the membrane currents were measured at the end of the test pulses. In WT mouse myocytes, small outward components of the $I_{\mathrm{K} 1}$ were observed at the membrane potentials that were more positive than $-90 \mathrm{mV}$ (Fig. 3a). The current-voltage ( $I-V$ ) relationship intersected with the abscissa at approximately $-95 \mathrm{mV}$ (filled circle in Fig. 3c). When the $I_{\mathrm{K} 1}$ was inhibited by $1 \mathrm{mM}$ barium $\left(\mathrm{Ba}^{2+}\right)$, no time-dependent currents were observed 

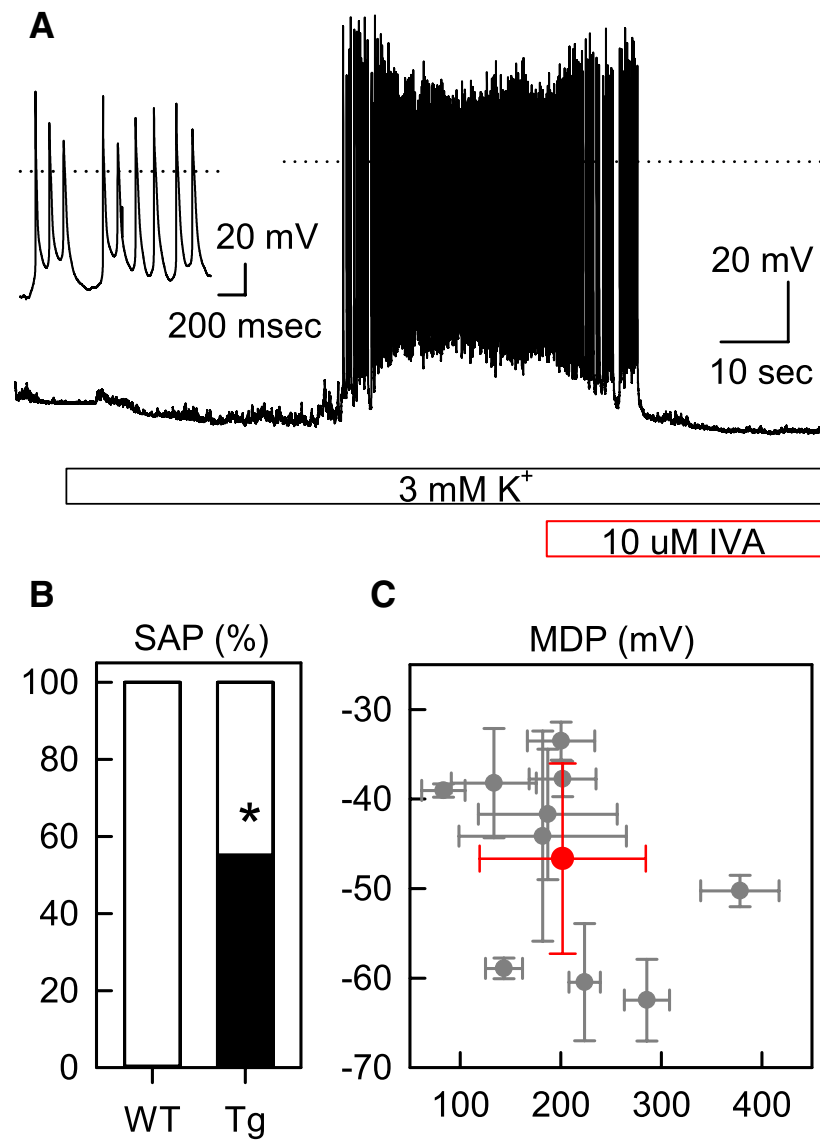

C
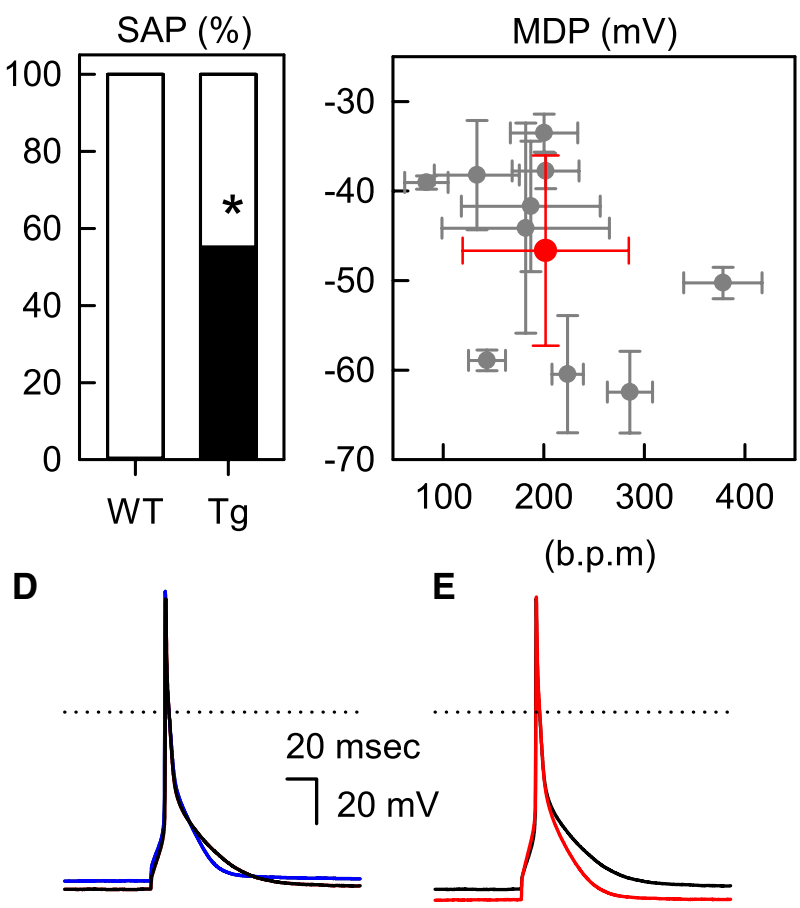

Fig. 2 Hypokalemia-induced spontaneous action potentials (SAPS) in the myocytes of transgenic mice overexpressing the hyperpolarization-activated, cyclic nucleotide-sensitive ( $\mathrm{HCN}$ ) channel in the heart (HCN2-Tg mice). a The perfusion with the $3 \mathrm{mM}\left[\mathrm{K}^{+}\right]_{\mathrm{o}}$ solution is shown by the blue bar. The RMP in the $5.4 \mathrm{mM}\left[\mathrm{K}^{+}\right]_{0}$ solution was $-81.4 \mathrm{mV}$. In the $3 \mathrm{mM}\left[\mathrm{K}^{+}\right]_{0}$ solution, the RMP was hyperpolarized to $-86.0 \mathrm{mV}$, followed by the generation of SAPs. The red bar indicates the perfusion with $10 \mu \mathrm{M}$ IVA. After the termination of the SAPs, the RMP was $-90.4 \mathrm{mV}$. The inset shows the expanded trace of the SAPs. b The incidences of SAPs (black portion of bar) in the $3 \mathrm{mM} \mathrm{K}^{+}$solution: WT, $0 \%$ (0 of 11 cells); HCN2-Tg, 55.0\% (11 of 20 cells). Asterisk indicates that difference is statistically significant at $p<0.01$ ( $\chi^{2}$ test). c The summary of firing rates (FRs) and maximal diastolic potentials (MDPs) of the SAPs. The gray symbols were obtained in each myocyte by averaging 10 successive SAPs. The red symbol indicates the mean values of the MDP $(-46.6 \pm 10.6 \mathrm{mV})$ and the FR $(201.8 \pm 82.6 \mathrm{bpm})$ averaged from 10 myocytes. d The induced AP of HCN2-Tg mouse myocytes in the $5.4 \mathrm{mM}\left[\mathrm{K}^{+}\right]_{0}$ solution (blue line) and $3 \mathrm{mM}\left[\mathrm{K}^{+}\right]_{\mathrm{o}}$ solution (black line). The RMP and action potential duration at $90 \%$ repolarization $\left(\mathrm{APD}_{90}\right)$ were $-83.8 \mathrm{mV}$ and $31.0 \mathrm{~ms}$, respectively, in the $5.4 \mathrm{mM}\left[\mathrm{K}^{+}\right]_{\mathrm{o}}$ solution and $-88.1 \mathrm{mV}$ and $36.8 \mathrm{~ms}$, respectively, in the $3 \mathrm{mM}$ $\left[\mathrm{K}^{+}\right]_{\mathrm{o}}$ solution. e. The effect of $10 \mu \mathrm{M}$ IVA on the AP in the $3 \mathrm{mM}\left[\mathrm{K}^{+}\right]_{\mathrm{o}}$ solution. The AP was recorded in the same HCN2-Tg mouse myocytes as those shown in $\mathbf{d}$ (the black line, control; the red line, with $10 \mu \mathrm{M}$ IVA). The application of IVA hyperpolarized the RMP from -88.1 to $-94.0 \mathrm{mV}$ and shortened the $\mathrm{APD}_{90}$ from 36.8 to $29.8 \mathrm{~ms}$ (color figure online)
Table 2 Summary of the parameters of induced action potentials in the myocytes of transgenic mice overexpressing the $\mathrm{HCN} 2$ channel in the heart

\begin{tabular}{lcrc}
\hline $\mathrm{HCN} 2-\mathrm{Tg}$ & $5.4 \mathrm{mM}\left[\mathrm{K}^{+}\right]_{\mathrm{o}}$ & $3 \mathrm{mM}\left[\mathrm{K}^{+}\right]_{\mathrm{o}}$ & $3 \mathrm{mM}\left[\mathrm{K}^{+}\right]_{\mathrm{o}}+\mathrm{IVA}$ \\
\hline $\mathrm{RMP}(\mathrm{mV})$ & $-82.1 \pm 2.4$ & $-91.2 \pm 3.3$ & $-93.4 \pm 2.9^{*}$ \\
$\mathrm{APD}_{90}(\mathrm{~ms})$ & $31.5 \pm 1.6$ & $37.1 \pm 3.1$ & $30.1 \pm 2.2^{*}$ \\
\hline
\end{tabular}

The summaries of RMP and $\mathrm{APD}_{90}$ in the $5.4 \mathrm{mM}\left[\mathrm{K}^{+}\right]_{0}, 3 \mathrm{mM}$ $\left[\mathrm{K}^{+}\right]_{0}$, and $3 \mathrm{mM}\left[\mathrm{K}^{+}\right]_{0}$ solutions, respectively, all of which contain $10 \mu \mathrm{M}$ IVA

HCN2-Tg Transgenic mice overexpressing the hyperpolarization-activated, cyclic nucleotide-sensitive ( $\mathrm{HCN})$ channel in the heart

*Significant difference at $p<0.05$ (paired $t$ test) in the presence and absence of IVA $(n=6)$

in WT mouse myocytes (Fig. 3b), indicating a linear $I-V$ relationship (open circle in Fig. 3c).

In HCN2-Tg mouse myocytes, the hyperpolarizing pulses activated both the $I_{\mathrm{HCN}}$ and $I_{\mathrm{K} 1}$, as shown in Fig. $3 \mathrm{~d}$. In the $I-V$ relationships measured in the $3 \mathrm{mM}\left[\mathrm{K}^{+}\right]_{0}$ solution, the outward components of the $I_{\mathrm{K} 1}$ were almost cancelled out by the overlapping activation of the $\mathrm{HCN}$-driven current $\left(I_{\mathrm{HCN}}\right)$ between -80 and $-60 \mathrm{mV}$ (filled circle in Fig. 3f). The application of $1 \mathrm{mM} \mathrm{Ba}^{2+}$ disclosed a robust activation of $I_{\mathrm{HCN}}$, as shown in Fig. 3e. The $I-V$ relationship measured in the presence of $\mathrm{Ba}^{2+}$ showed a clear inward-rectification at the membrane potentials more negative than $-70 \mathrm{mV}$, which was due to the activation of the $I_{\mathrm{HCN}}$ (open circle in Fig. 3f). These $I-V$ relationships comprehensively explained the unstable, depolarized RMP of HCN2-Tg mouse myocytes in $3 \mathrm{mM}\left[\mathrm{K}^{+}\right]_{\mathrm{o}}$ solution.

\section{The activation curves of $I_{\mathrm{HCN}}$ in hypokalemic solution}

It is well known that extracellular $\mathrm{K}^{+}$has multiple effects on the biophysical properties of $I_{\mathrm{HCN}}[11]$. First, $\mathrm{K}^{+}$itself is highly permeable through $\mathrm{HCN}$ channels. The permeability ratio for $\mathrm{K}^{+}$and $\mathrm{Na}^{+}\left(P_{\mathrm{Na}} / P_{\mathrm{K}}\right)$ was $0.20-0.25$, depending on the extracellular $\mathrm{K}^{+}$concentration. Second, extracellular $\mathrm{K}^{+}$ is an activator of $I_{\mathrm{HCN}}$, maintaining the ionic conductance through the $\mathrm{HCN}$ channels. Third, extracellular $\mathrm{K}^{+}$modulates the voltage-dependence of $I_{\mathrm{HCN}}$ activation when the $\mathrm{K}^{+}$ concentration of the bathing solution is increased to nonphysiological levels (i.e., 30 or $100 \mathrm{mM}$ ).

Therefore, we examined the voltage dependence of $I_{\mathrm{HCN}}$ in HCN2-overexpressing ventricular myocytes under hypokalemic conditions. $I_{\mathrm{HCN}}$ was recorded in the same myocytes immersed in a $5.4 \mathrm{mM}\left[\mathrm{K}^{+}\right]_{\mathrm{o}}$ solution (Fig. 4a) and in a $3 \mathrm{mM}\left[\mathrm{K}^{+}\right]_{\mathrm{o}}$ bathing solution (Fig. 4b). In these experiments, $I_{\mathrm{K} 1}$ was suppressed by the addition of $1 \mathrm{mM}$ $\mathrm{Ba}^{2+}$. The amplitude of $I_{\mathrm{HCN}}$ decreased under hypokalemic conditions; at $-150 \mathrm{mV}$, the amplitude of $I_{\mathrm{HCN}}$ in 
A

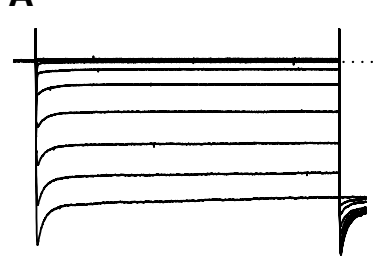

D

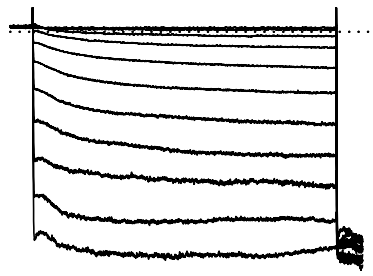

B

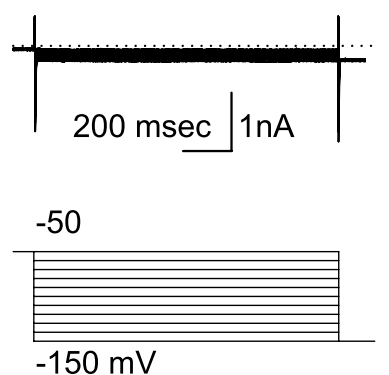

E

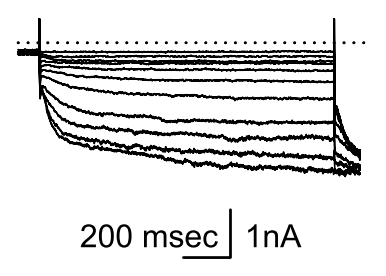

C

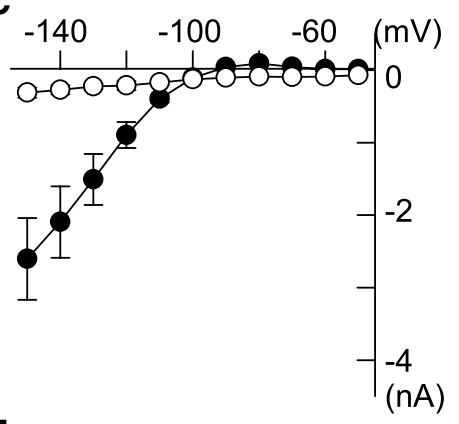

$\mathbf{F}$

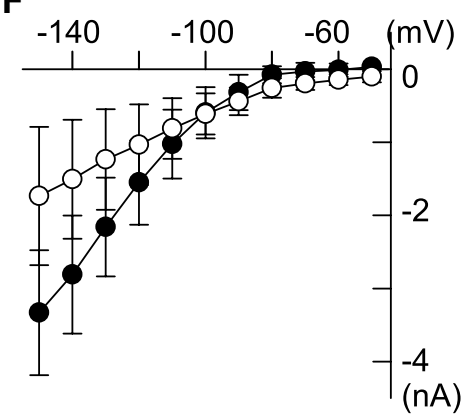

Fig. 3 The current-voltage ( $I-V)$ relationships of WT and HCN2-Tg mouse myocytes in $3 \mathrm{mM} \mathrm{K}{ }^{+}$solution. a The current traces of WT myocytes recorded in the control condition. $\mathbf{b}$ The current traces of WT myocytes in the presence of $1 \mathrm{mM}$ barium $\left(\mathrm{Ba}^{2+}\right)$. The inset shows the pulse protocol. c The $I-V$ relationships of the background current of WT mouse myocytes. The amplitudes of the background current were measured at the end of the hyperpolarizing pulses: filled circle, control; open circle, in the presence of $1 \mathrm{mM} \mathrm{Ba}^{2+}$. $\mathbf{d}$ The current traces of HCN2-Tg myocytes in the cotrol condition. e The current traces of HCN2-Tg myocytes in the presence of $1 \mathrm{mM} \mathrm{Ba}^{2+}$. $\mathbf{f}$ The $I-V$ relationships measured in HCN2-Tg myocytes (same conditions as in $\mathbf{c})$
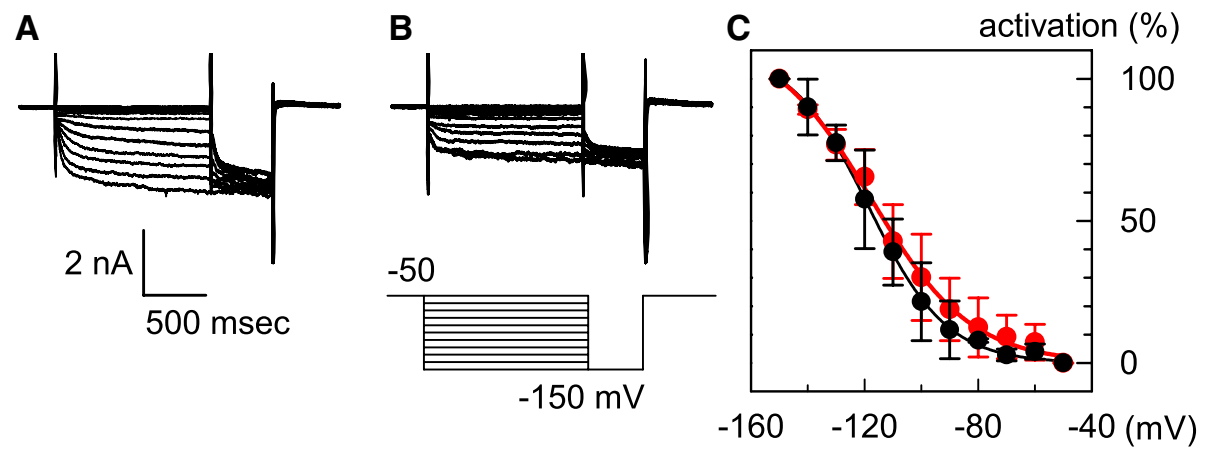

Fig. 4 The activation curves of $I_{\mathrm{HCN}}$ in $5.4 \mathrm{mM}\left[\mathrm{K}^{+}\right]_{\mathrm{o}}$ and $3 \mathrm{mM}$ $\left[\mathrm{K}^{+}\right]_{\mathrm{o}}$ bathing solution. a $I_{\mathrm{HCN}}$ recorded in the $5.4 \mathrm{mM}\left[\mathrm{K}^{+}\right]_{\mathrm{o}}$ solution; $I_{\mathrm{K} 1}$ was suppressed by $1 \mathrm{mM} \mathrm{Ba}{ }^{2+}$. b $I_{\mathrm{HCN}}$ in the $3 \mathrm{mM}\left[\mathrm{K}^{+}\right]_{\mathrm{o}}$ solution. The $I_{\mathrm{HCN}}$ was recorded in the same HCN2-Tg mouse myocytes as those mentioned in $\mathbf{a}$. The pulse protocol is indicated below the traces. c The activation curves of $I_{\mathrm{HCN}}$ in the $5.4 \mathrm{mM}\left[\mathrm{K}^{+}\right]_{\mathrm{o}}$

the $3 \mathrm{mM}\left[\mathrm{K}^{+}\right]_{\mathrm{o}}$ bathing solution was $55.6 \pm 13.9 \%$ of that in the $5.4 \mathrm{mM}\left[\mathrm{K}^{+}\right]_{0}$ normal Tyrode solution $(n=6)$. In order to obtain the voltage-dependent activation curve, we applied conditioning pulses (from -50 to $-150 \mathrm{mV}$ ), followed by the test pulse $(-150 \mathrm{mV})$. The amplitudes of the time-dependent components during the test pulse were normalized by the maximal value; these are plotted solution (filled black circles) and in $3 \mathrm{mM}\left[\mathrm{K}^{+}\right]_{\mathrm{o}}$ solution (filled red circles). The $V_{1 / 2}$ (membrane potential for half-maximal activation) was $-118.5 \pm 2.9 \mathrm{mV}$ (in the $5.4 \mathrm{mM}\left[\mathrm{K}^{+}\right]_{\mathrm{o}}$ solution) and $-117.7 \pm 3.4 \mathrm{mV}$ (in the $3 \mathrm{mM}\left[\mathrm{K}^{+}\right]_{\mathrm{o}}$ solution) $(n=6)$ (color figure online)

in Fig. 4c. The black and red symbols in Fig. 4c indicate the activation curves obtained in the $5.4 \mathrm{mM}\left[\mathrm{K}^{+}\right]_{\mathrm{o}}$ solution and $3 \mathrm{mM}\left[\mathrm{K}^{+}\right]_{\mathrm{o}}$ solution, respectively. The lines in the case of each group of data were fitted using the Boltzmann's equation:

$\%$ activation $=1 /\left(1+\exp \left(\left(V_{\mathrm{m}}-V_{1 / 2}\right) / s\right)\right)$, 
A

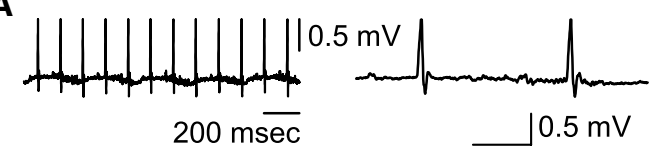

B

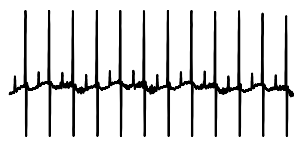

C
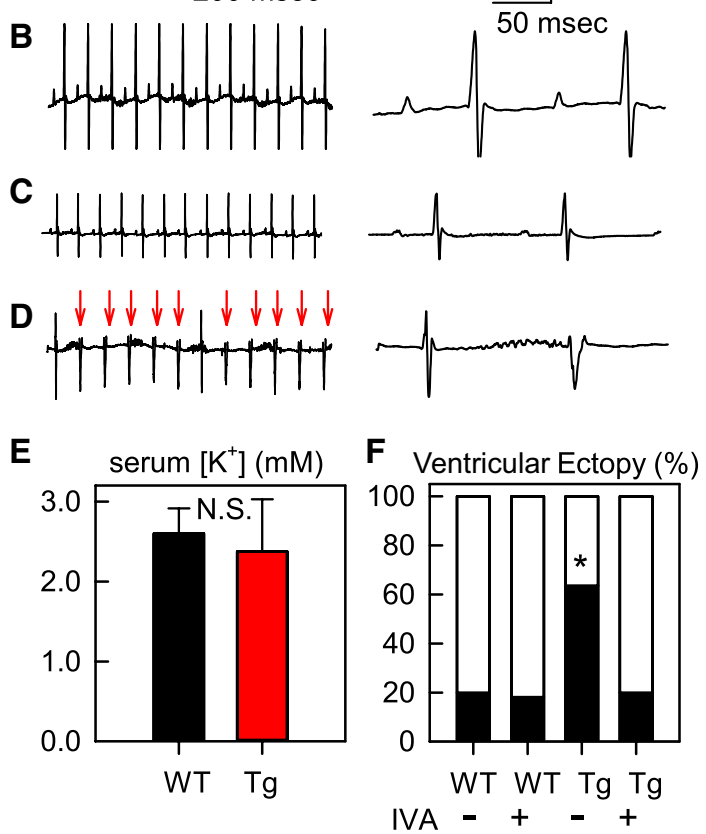

Fig. 5 The electrocardiogram (ECG) recordings of WT and HCN2-Tg mice after they were fed a $\mathrm{K}^{+}$-free diet for 6 weeks. a ECG of WT mouse under control conditions. b ECG of a WT mouse after 6 weeks on a $\mathrm{K}^{+}$-free diet. c ECG of HCN2-Tg mouse under control conditions. d ECG of a HCN2-Tg mouse after 6 weeks on a $\mathrm{K}^{+}$-free diet. Ventricular ectopy (VE) is indicated by red arrows in all cases. In a-d, the panels to the left show the expanded traces. e Serum $\mathrm{K}^{+}$concentrations measured after the ECG recordings. N.S. Not signficant. f Summary of the incidence of VE. In each experiment, ECGs were recorded for $5 \mathrm{~min}$ to confirm the incidence of VE. Asterisk indicates significant difference $\left(\chi^{2}\right.$ test, $\left.p<0.01\right)$ (color figure online)

where $V_{\mathrm{m}}$ is the membrane potential; $V_{1 / 2}$ is the membrane potential for half-maximal activation; and $s$ is the slope factor. As shown in Fig. $4 \mathrm{c}$, the $V_{1 / 2}$ in the case of the $3 \mathrm{mM} \mathrm{K}^{+}$ solution was $-117.7 \pm 3.4 \mathrm{mV}(n=6)$. This value was not significantly different from that in the case of the $5.4 \mathrm{mM}$ $\mathrm{K}^{+}$solution $(-118.5 \pm 2.9 \mathrm{mV}, n=6)$. These results indicate that approximately $18 \%$ of the $I_{\mathrm{HCN}}$ was activated at the RMP of $\mathrm{HCN} 2-\mathrm{Tg}$ mouse myocytes in the $3 \mathrm{mM}\left[\mathrm{K}^{+}\right]_{0}$ solution.

\section{Ventricular ectopy induced by hypokalemia in HCN2-Tg mice}

We next examined whether hypokalemia could induce ventricular arrhythmia in HCN2-Tg mice in vivo. As we reported previously, and as seen in Fig. 5a, b, ECG waveforms of WT and HCN2-Tg mice did not differ significantly under control conditions [9]. To record ECGs under hypokalemic conditions, we raised the WT and HCN2-Tg mice on a
Table 3 Electrocardiogram parameters of wild-type mice and transgenic mice overexpressing the $\mathrm{HCN} 2$ channel

\begin{tabular}{llll}
\hline ECG parameters & Test conditions $^{\mathrm{a}}$ & WT mice & HCN2-Tg mice \\
\hline RR (s) & CTR & $0.121 \pm 0.013$ & $0.113 \pm 0.06$ \\
& Hypokalemia & $0.174 \pm 0.015^{*}$ & $0.139 \pm 0.022^{*}$ \\
PQ (s) & CTR & $0.039 \pm 0.008$ & $0.038 \pm 0.005$ \\
& Hypokalemia & $0.048 \pm 0.004^{*}$ & $0.047 \pm 0.005^{*}$ \\
QT (s) & CTR & $0.042 \pm 0.006$ & $0.042 \pm 0.006$ \\
& Hypokalemia & $0.072 \pm 0.005^{*}$ & $0.067 \pm 0.003^{*}$ \\
QTc (s) & CTR & $0.119 \pm 0.017$ & $0.125 \pm 0.007$ \\
& Hypokalemia & $0.189 \pm 0.022$ & $0.179 \pm 0.018^{*}$ \\
\hline
\end{tabular}

ECG, Electrocardiogram

*Significant difference between the values of CTR and hypokalemia at $p<0.05$ ( $t$ test $)(n=3-6)$

${ }^{a}$ The control ECGs (CTR) were recorded before the mice were started on the $\mathrm{K}^{+}$-free diet. The ECGs in the hypokalemic condition (Hypokalemia) were recorded after the mice had been fed a $\mathrm{K}^{+}$-free diet for 6 weeks

${ }^{\mathrm{b}} \mathrm{QTc}$ was calculated according to Bazett's formula

$\mathrm{K}^{+}$-free diet for 6 weeks [12], following which we recorded the ECGs and then measured serum $\mathrm{K}^{+}$concentrations. The magnitudes of hypokalemia in the WT and HCN2-Tg mice again did not differ significantly (Fig. 5c: WT, black bar, $2.6 \pm 0.3 \mathrm{mM}$; HCN2-Tg, red bar, $2.4 \pm 0.6 \mathrm{mM} ; n=3)$. As summarized in Table 3, the ECG parameters (RR, PQ, QT, and QTc) were significantly prolonged by hypokalemia in both WT and HCN2-Tg mice, although no significant difference was found between the ECG parameters of WT and HCN2-Tg mice irrespective of the hypokalemia.

Notably, ventricular ectopy (VE) was recorded in $63.6 \%$ of HCN2-Tg mice, as indicated by the red arrows in Fig. $5 \mathrm{~d}$ ( $n=7$ of 11 mice). Similar VE was also observed in $20.0 \%$ of the WT mice (data not shown, 2 of 10 mice). We have previously reported that the VE induced by $\beta$-adrenergic stimulation in HCN2-Tg mice was successfully inhibited by IVA [7]. Likewise, in the present study the oral application of IVA reduced the incidence of VE in HCN2-Tg mice (to $20.0 \%, n=2$ of 10 ). As summarized in Fig. 5f, the incidence of VE induced by the $\mathrm{K}^{+}$-free diet was significantly higher in the HCN2-Tg mice not subjected to IVA treatment $\chi^{2}$ test, $p<0.01)$. Lethal arrhythmias, such as ventricular tachycardia (VT) or ventricular fibrillation (VF) were observed in neither the WT ( $n=0$ of 11$)$ nor the HCN2-Tg ( $n=0$ of 10) mice.

\section{Discussion}

Hypokalemia is known to have a pro-arrhythmic effect even in the normal heart. In heart failure patients, activation of the renin-angiotensin-aldosterone system is known 
to induce hypokalemia. Diuretic treatment also exacerbates hypokalemia [4]. However, the effects of hypokalemia on failing hearts that undergo electrophysiological remodeling remain poorly understood. We had previously reported that $\mathrm{HCN}$ channels were re-expressed in the ventricular myocytes of a mouse model of heart failure [6]. In the present study, we demonstrated that HCN2-overexpressing ventricular myocytes showed a higher vulnerability to arrhythmia even under mild, commonly observed hypokalemic conditions.

Serum $\mathrm{K}^{+}$concentration is strictly regulated within a narrow range $(3.5-5.0 \mathrm{mM})$ by many organs in the human body, and a serum $\mathrm{K}^{+}$concentration of $<3.5 \mathrm{mM}$ is clinically defined as hypokalemia [4]. Hypokalemia promotes ventricular arrhythmias, such as VE, Torsades de Pointes, $\mathrm{VT}$, and VF, due to its effect of increasing the electrical instability of cardiac myocytes, mainly by two mechanisms. First, hypokalemia prolongs the APD and induces early after-depolarization (EAD) by decreasing the repolarization reserve of the ventricular AP [8, 13]. Second, hypokalemia inhibits the activity of $\mathrm{Na}^{+}-\mathrm{K}^{+}$ATPase (NKA) and decreases the amplitude of outward pump currents, which also contribute to the repolarization reserve [14]. It has also been reported that the inhibition of NKA promotes intracellular $\mathrm{Na}^{+}$accumulation and intracellular $\mathrm{Ca}^{2+}$ overload via the consequent decrease in the driving force of the $\mathrm{Na}^{+}-\mathrm{Ca}^{2+}$ exchanger (NCX) $[2,14,15]$. Under this condition, spontaneous $\mathrm{Ca}^{2+}$ sparks are increased by calmodulin kinase II (CaMKII) via the phosphorylation of the ryanodine receptor (RyR), inducing the inward current carried by NCX $[14,15]$. CaMKII may also activate the late $\mathrm{Na}^{+}$current $\left(I_{\mathrm{Na}}\right)$ and L-type $\mathrm{Ca}^{2+}$ current $\left(I_{\mathrm{Ca}-\mathrm{L}}\right)[14]$. EAD has been reported to be induced by these mechanisms 10-50 min after the ex vivo perfusion of rabbit hearts with a hypokalemic solution [14]. The $\mathrm{Ca}^{2+}$ overload may also promote ventricular arrhythmia by activating the transient receptor potential channels [16].

In addition to the above mechanisms, based on our results we propose a novel mechanism underlying hypokalemia-induced arrhythmia in failing hearts, whereby the HCN channels overexpressed in the heart are constitutively activated at hyperpolarized RMPs under hypokalemic conditions, resulting in destabilization of the RMP. As shown in Fig. 2, SAP was induced in 55\% of HCN2-Tg mouse myocytes; in the remaining HCN2-Tg mouse myocytes, the RMP in the hypokalemic solution was further hyperpolarized by IVA treatment. It should be noted that Chen et al. reported that when HCN2 and Kir2.1 were co-expressed in HEK293 cells, the RMP of these cells oscillated between -64 and $-34 \mathrm{mV}$, depending on the balance between the expression levels of $\mathrm{HCN} 2$ and Kir2.1 [17]. Based on the same rationale, we suggest that the diversity of hypokalemic responses in $\mathrm{HCN} 2-\mathrm{Tg}$ mouse myocytes may be due to variation in the HCN2 expression levels, such that when the oscillation of RMP exceeds the threshold of $I_{\mathrm{Na}}$, HCN2-Tg mouse myocytes may start to fire. The SAPs that follow may be due to the activation of $I_{\mathrm{Ca}-\mathrm{L}}$; a similar mechanism for EADs has been reported in rabbit myocytes [8]. The reversal potential of $I_{\mathrm{HCN}}$ was approximately $-35 \mathrm{mV}$ in the hypokalemic solution. Therefore, the inward $I_{\mathrm{HCN}}$ should decrease the repolarization reserve at membrane potentials that are more negative than $-35 \mathrm{mV}$. In fact, we observed that the APD of quiescent HCN-Tg mouse myocytes was significantly longer under hypokalemic conditions. This finding agrees well with that of our previous study in which $I_{\mathrm{HCN}}$ activated by $\beta$-adrenergic stimulation was shown to have a similar effect on the APD of HCN2-Tg mouse myocytes [9].

\section{Limitations of the present study}

In this study, we employed the ruptured whole-cell patch method using a pipette solution containing EGTA in order to focus on the arrhythmogenic role of the ion channels expressed on the plasma membrane. However, it has been reported that the plateau phase of the AP of murine ventricular myocytes is at approximately $-40 \mathrm{mV}$, and is generated by the NCX current [18]. Therefore, the participation of the intracellular $\mathrm{Ca}^{2+}$ transient in the configuration of the AP may have been underestimated; i.e., when the intracellular $\mathrm{Ca}^{2+}$ transient was kept intact, APD may have been more prominently prolonged under hypokalemic conditions. At the given composition of the bathing solution, the inward $I_{\mathrm{HCN}}$ current was mainly carried by external $\mathrm{Na}^{+}$. Therefore, under hypokalemic conditions, it appears likely that the constitutive activation of $I_{\mathrm{HCN}}$ may lead to intracellular $\mathrm{Na}^{+}$ accumulation and, consequently, $\mathrm{Ca}^{2+}$ overload in $\mathrm{HCN} 2-\mathrm{Tg}$ mouse myocytes. Future studies should measure the intracellular $\mathrm{Na}^{+}$and $\mathrm{Ca}^{2+}$ transients of HCN2-Tg mouse myocytes under hypokalemic conditions.

The APD of murine ventricular myocytes is much shorter than that of myocytes of larger animals, mainly due to the different expression pattern of repolarizing $\mathrm{K}^{+}$channels. The repolarization reserve of rabbit myocytes reportedly consists of $I_{\mathrm{Kr}}(\mathrm{Kv} 11.1)$ and $I_{\mathrm{K} 1}$; the conductance of both these components is highly sensitive to $\left[\mathrm{K}^{+}\right]_{\mathrm{o}}[19]$. In contrast, $I_{\mathrm{Kr}}$ is not expressed in murine myocytes. The voltage-gated $\mathrm{K}^{+}$channels expressed in murine myocytes are: $\mathrm{Kv} 4.2$ (fast component of transient outward current; $I_{\text {to, fast }}$ ), Kv1.4 (slow component of transient outward current; $\left.I_{\text {to, slow }}\right), \mathrm{Kv} 1.5$

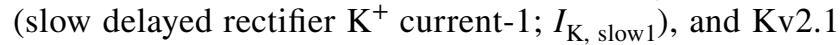
(slow delayed rectifier $\mathrm{K}^{+}$current-2; $I_{\mathrm{K} \text {, slow2 }}$ ) [19]. The conductance of Kv1.4 [20], Kv1.5 [21], and Kv2.1 [22] are reportedly less sensitive to $\left[\mathrm{K}^{+}\right]_{\mathrm{o}}$ than that of $I_{\mathrm{K} 1}[23]$ or $I_{\mathrm{Kr}}$ [24]. Therefore, under hypokalemic conditions, the decrease in the repolarization reserve in murine hearts may not be as 
remarkable as that in the hearts of larger animals. For this reason, lethal arrhythmia may not have been induced in vivo by hypokalemia. Future studies should examine the effects of hypokalemia in the myocytes isolated from hypertrophied hearts of larger animals, such as rabbits, following electrophysiological remodeling.

Acknowledgements This work was supported by JSPS KAKENHI Grant number 16H05124. The authors thank Ms. Akemi Sakamoto and Ms. Hideko Yoshitake. for the secretary work.

\section{Compliance with ethical standards}

Conflict of interest The authors declare that they have no conflict of interest.

Statement of animal/human rights Procedures for animal experiments were approved in advance by the Animal Ethics Committee of Kurume University (No. 2018-016), in accordance with the Guidelines for the Care and Use of Laboratory Animals published by the US National Institute of Health (NIH Publication No. 85-23, revised 1996).

Open Access This article is distributed under the terms of the Creative Commons Attribution 4.0 International License (http://creativeco mmons.org/licenses/by/4.0/), which permits unrestricted use, distribution, and reproduction in any medium, provided you give appropriate credit to the original author(s) and the source, provide a link to the Creative Commons license, and indicate if changes were made.

\section{References}

1. Osadchii OE (2010) Mechanisms of hypokalemia-induced ventricular arrhythmogenicity. Fundam Clin Pharmacol 24:547-559

2. Skogestad J, Aronsen JM (2018) Hypokalemia-induced arrhythmias and heart failure: new insights and implications for therapy. Front Physiol 9:1500. doi: https://doi.org/10.3389/fphys.2018.01500

3. Cooper HA, Dries DL, Davis CE, Shen YL, Domanski MJ (1999) Diuretics and risk of arrhythmic death in patients with left ventricular dysfunction. Circulation 100:1311-1315

4. Macdonald JE, Struthers AD (2004) What is the optimal serum potassium level in cardiovascular patients? J Am Coll Cardiol 43:155-161

5. Johnson DM, Antoons G (2018) Arrhythmogenic mechanisms in heart failure: linking $\beta$-adrenergic stimulation, stretch, and calcium. Front Physiol 9:1453. doi: https://doi.org/10.3389/fphys.2018.01453

6. Kuwahara K, Saito Y, Takano M, Arai Y, Yasuno S, Nakagawa Y, Takahashi N, Adachi Y, Takemura G, Horie M, Miyamoto Y, Morisaki T, Kuratomi S, Noma A, Fujiwara H, Yoshimasa Y, Kinoshita H, Kawakami R, Kishimoto I, Nakanishi M, Usami S, Saito Y, Harada M, Nakao K (2003) NRSF regulates the fetal cardiac gene program and maintains normal cardiac structure and function. EMBO J 22:6310-6321

7. Kuwabara Y, Kuwahara K, Takano M, Kinoshita H, Arai Y, Yasuno S, Nakagawa Y, Igata S, Usami S, Minami T, Yamada Y, Nakao K, Yamada C, Shibata J, Nishikimi T, Ueshima K, Nakao K (2013) Increased expression of $\mathrm{HCN}$ channels in the ventricular myocardium contributes to enhanced arrhythmicity in mouse failing hearts. J Am Heart Assoc 2:e000150

8. Trenor B, Cardona K, Romero L, Gomez JF, Saiz J, Rajamani S, Belardinelli L, Giles W (2018) Pro-arrhythmic effects of low plasma $\left[\mathrm{K}^{+}\right]$in human ventricle: an illustrated review. Trends Cardiovasc Med 28:233-242
9. Oshita K, Itoh M, Hirashima S, Kuwabara Y, Ishihara K, Kuwahara K, Nakao K, Kimura T, Nakamura K, Ushijima K, Takano M (2015) Ectopic automaticity induced in ventricular myocytes by transgenic overexpression of HCN2. J Mol Cell Cardiol 80:81-89

10. Oshita K, Kozasa Y, Kuwabara Y, Kuwahara K, Ushijima K, Takano M (2018) Hypokalemia-induced ventricular arrhythmogenicity is increased in transgenic mice overexpressing $\mathrm{HCN} 2$ specifically in the heart. J Physiol Sci 68:S174

11. Biel M, Wahl-Schott C, Michalakis S, Zong X (2009) Hyperpolarization-activated cation channels: from genes to function. Physiol Rev 89:847-885

12. Guo J, Massaeli H, Xu J, Jia Z, Wigle JT, Mesaeli N, Zhang S (2009) Extracellular $\mathrm{K}^{+}$concentration controls cell surface density of $I_{\mathrm{Kr}}$ in rabbit hearts and of the HERG channel in human cell lines. J Clin Invest 119:2745-2757

13. Qu Z, Xie LH, Olcese R, Karagueuzian HS, Chen PS, Garfinkel A, Weiss JN (2013) Early afterdepolarizations in cardiac myocytes: beyond reduced repolarization reserve. Cardiovasc Res 99:6-15

14. Pezhouman A, Singh N, Song Z, Nivala M, Eskandari A, Cao H, Bapat A, Ko CY, Nguyen T, Qu Z, Karagueuzian HS, Weiss JN (2015) Molecular basis of hypokalemia-induced ventricular fibrillation. Circulation 132:1528-1537

15. Aronsen JM, Skogestad J, Lewalle A, Louch WE, Hougen K, Stokke MK, Swift F, Niederer S, Smith NP, Sejersted OM, Sjaastad I (2015) Hypokalaemia induces $\mathrm{Ca}^{2+}$ overload and $\mathrm{Ca}^{2+}$ waves in ventricular myocytes by reducing $\mathrm{Na}^{+}, \mathrm{K}^{+}$-ATPase $\alpha_{2}$ activity. J Physiol 593:1509-1521

16. Hu Y, Duan Y, Takeuchi A, Hai-Kurahara L, Ichikawa J, Hiraishi K, Numata T, Ohara H, Iribe G, Nakaya M, Mori MX, Matsuoka S, Ma G, Inoue R (2017) Uncovering the arrhythmogenic potential of TRPM4 activation in atrial-derived HL-1 cells using novel recording and numerical approaches. Cardiovasc Res 113:1243-1255

17. Chen K, Zuo D, Wang SY, Chen H (2018) Kir2 inward rectificationcontrolled precise and dynamic balances between Kir2 and $\mathrm{HCN}$ currents initiate pacemaking activity. FASEB J 32:3047-3057

18. Takano M, Kinoshita H, Shioya T, Itoh M, Nakao K, Kuwahara K (2010) Phathophysiological remodelling of mouse cardiac myocytes expressing dominant negative mutant of neuron restrictive silencing factor. Circ J 74:2712-2719

19. Nerbonne JM (2014) Mouse models of arrhythmogenic cardiovascular disease: challenges and opportunities. Curr Opin Pharmacol 15:107-114

20. Claydon TW, Makary SY, Dibb KM, Boyett MR (2004) $\mathrm{K}^{+}$activation of kir3.1/kir3.4 and kv1.4 $\mathrm{K}^{+}$channels is regulated by extracellular charges. Biophys J 87:2407-2418

21. Fedida D, Zhang S, Kwan DC, Eduljee C, Kehl SJ (2005) Synergistic inhibition of the maximum conductance of Kv1.5 channels by extracellular $\mathrm{K}^{+}$reduction and acidification. Cell Biochem Biophys 43:231-242

22. Consiglio JF, Andalib P, Korn SJ (2003) Influence of pore residues on permeation properties in the Kv2.1 potassium channel. Evidence for a selective functional interaction of $\mathrm{K}^{+}$with the outer vestibule. J Gen Physiol 121:111-124

23. Ishihara $K(2018)$ External $\mathrm{K}^{+}$dependence of strong inward rectifier $\mathrm{K}^{+}$channel conductance is caused not by $\mathrm{K}^{+}$but by competitive pore blockade by external $\mathrm{Na}^{+}$. J Gen Physiol 150:977-989

24. Perry MD, Ng CA, Mann SA, Sadrieh A, Imtiaz M, Hill AP, Vandenberg JI (2015) Getting to the heart of hERG K${ }^{+}$channel gating. J Physiol 593:2575-2585

Publisher's Note Springer Nature remains neutral with regard to jurisdictional claims in published maps and institutional affiliations. 